\title{
ROS generated by pollen NADPH oxidase provide a signal that augments antigen- induced allergic airway inflammation
}

\author{
Istvan Boldogh, ${ }^{1}$ Attila Bacsi, ${ }^{1}$ Barun K. Choudhury, ${ }^{2}$ Nilesh Dharajiya, ${ }^{2}$ Rafeul Alam, ${ }^{3}$ \\ Tapas K. Hazra, ${ }^{4}$ Sankar Mitra, ${ }^{4}$ Randall M. Goldblum, ${ }^{5}$ and Sanjiv Sur ${ }^{2}$ \\ 1Department of Microbiology and Immunology and ${ }^{2} \mathrm{NIH}$ Asthma and Allergic Diseases Research Center and Department of Internal Medicine, \\ University of Texas Medical Branch (UTMB), Galveston, Texas, USA. ${ }^{3}$ Division of Allergy and Immunology, Department of Medicine, National Jewish Medical \\ and Research Center, Denver, Colorado, USA. ${ }^{4}$ Human Biological Chemistry and Genetics and ${ }^{5}$ Department of Pediatrics, UTMB, Galveston, Texas, USA.
}

\begin{abstract}
Pollen exposure induces allergic airway inflammation in sensitized subjects. The role of antigenic pollen proteins in the induction of allergic airway inflammation is well characterized, but the contribution of other constituents in pollen grains to this process is unknown. Here we show that pollen grains and their extracts contain intrinsic NADPH oxidases. The pollen NADPH oxidases rapidly increased the levels of ROS in lung epithelium as well as the amount of oxidized glutathione (GSSG) and 4-hydroxynonenal (4-HNE) in airwaylining fluid. These oxidases, as well as products of oxidative stress (such as GSSG and 4-HNE) generated by these enzymes, induced neutrophil recruitment to the airways independent of the adaptive immune response. Removal of pollen NADPH oxidase activity from the challenge material reduced antigen-induced allergic airway inflammation, the number of mucin-containing cells in airway epithelium, and antigen-specific IgE levels in sensitized mice. Furthermore, challenge with $A m b$ a 1, the major antigen in ragweed pollen extract that does not possess NADPH oxidase activity, induced low-grade allergic airway inflammation. Addition of GSSG or 4-HNE to Amb a 1 challenge material boosted allergic airway inflammation. We propose that oxidative stress generated by pollen NADPH oxidases (signal 1) augments allergic airway inflammation induced by pollen antigen (signal 2).
\end{abstract}

\section{Introduction}

Asthma is an inflammatory disease of the airways that is characterized by airway eosinophilia, mucin production, IgE production, and airway hyperresponsiveness (AHR). Eosinophilic inflammation has been correlated with the severity of asthma (1), and fatal asthma is associated with accumulation of eosinophils in airway mucosa and submucosa $(2,3)$. A recent study conducted in transgenic mice lacking eosinophils demonstrated the unequivocal importance of eosinophils in allergic inflammation and experimental asthma (4). Because eosinophils play a key role in the pathogenesis of asthma, many animal models have been developed to study its recruitment into the lungs during allergic inflammation. We and others have shown that in patients with allergic asthma as well as in sensitized mice, challenge with ragweed pollen extract (RWE) induces recruitment of eosinophils to the lungs (5-10), which is associated with AHR, mucin production, and IgE production (9-13). Recruitment of eosinophils in these models

Nonstandard abbreviations used: AHR, airway hyperresponsiveness; BAL, bronchoalveolar lavage; DCF, dichlorofluorescein; DPI, diphenyleneiodonium; GSSG, oxidized glutathione; $\mathrm{H}_{2} \mathrm{DCF}-\mathrm{DA}, 2^{\prime}$ - 7 '-dihydro-dichlorofluorescein diacetate; HDM, house dust mite; 4-HNE, 4-hydroxynonenal; MDA, malondialdehyde; MDCK, Madin-Darby canine kidney; NAC, N-acetylcysteine; NBT, nitroblue tetrazolium; NCI, National Cancer Institute; NHBE cell, normal human bronchial epithelial cell; $\mathrm{O}_{2}{ }^{-}$, superoxide radical anion(s); PCBER, phenylcoumaran benzylic ether reductase; pRWE, purified RWE; $p$ RWE ${ }^{\mathrm{OX}^{+}}$, pRWE fractions with NADPH oxidase activity; PRWE ${ }^{O X-}$, pRWE fractions without NADPH oxidase activity; QA, quinancrine; RWE, ragweed pollen extract; $\mathrm{RWE}^{\mathrm{H}}$, heat-inactivated RWE; SOD, superoxide dismutase; $\mathrm{XO}$, xanthine oxidase; $\mathrm{X}+\mathrm{XO}$, xanthine and $\mathrm{XO}$.

Conflict of interest: The authors have declared that no conflict of interest exists.

Citation for this article: J. Clin. Invest. 115:2169-2179 (2005).

doi:10.1172/JCI24422. during allergic lung inflammation peaks at 24-72 hours after challenge $(5-7,9,10,14)$. However, the very early events that occur in the airways after pollen exposure have not been characterized.

Pollens are complex biological packages composed of many proteins. Inhalation of pollens in sensitized subjects can induce symptoms of seasonal asthma and allergic rhinitis $(15,16)$. Pollen grains and subpollen particles can penetrate into lower airways and exacerbate asthma $(17,18)$. Exposure to pollens such as ragweed in allergic subjects has been shown to induce prolonged bronchial obstruction and airway inflammation $(7,19)$. Pollens contain various antigenic proteins such as the pectate lyase Amb a 1 in ragweed, defensin-like Art v 1 in mugwort, Ole e 1-like allergens Pla 11 in plantain and Che a 1 in goosefoot, and nonspecific lipid transfer proteins Par j 1 and Par j 2 in pellitory (20). These antigenic proteins are processed in antigen-presenting cells and presented to Th2 cells, thereby triggering an adaptive immune response.

In addition to these antigens, pollens contain myriads of other proteins, some with enzymatic activities. An unresolved question is whether enzymatic activities in pollens directly induce oxidative stress prior to inflammation. Plant cells contain NADPH oxidases similar to those found in mammalian phagocytes (21-24). These plant oxidases play a critical role in vital physiological functions, including defense against pathogens (25-27) and growth and development $(24,28,29)$. A recent study has demonstrated that ROS produced by NADPH oxidases regulate expansion of cells in root hairs (30). Pollens have many enzymatic activities (31), but to our knowledge, the presence of NADPH oxidases has not previously been reported. Since pollen germination and formation of the pollen tubes are likely to require ROS, we sought to determine whether pollen grains contain NADPH oxidases and, if so, 

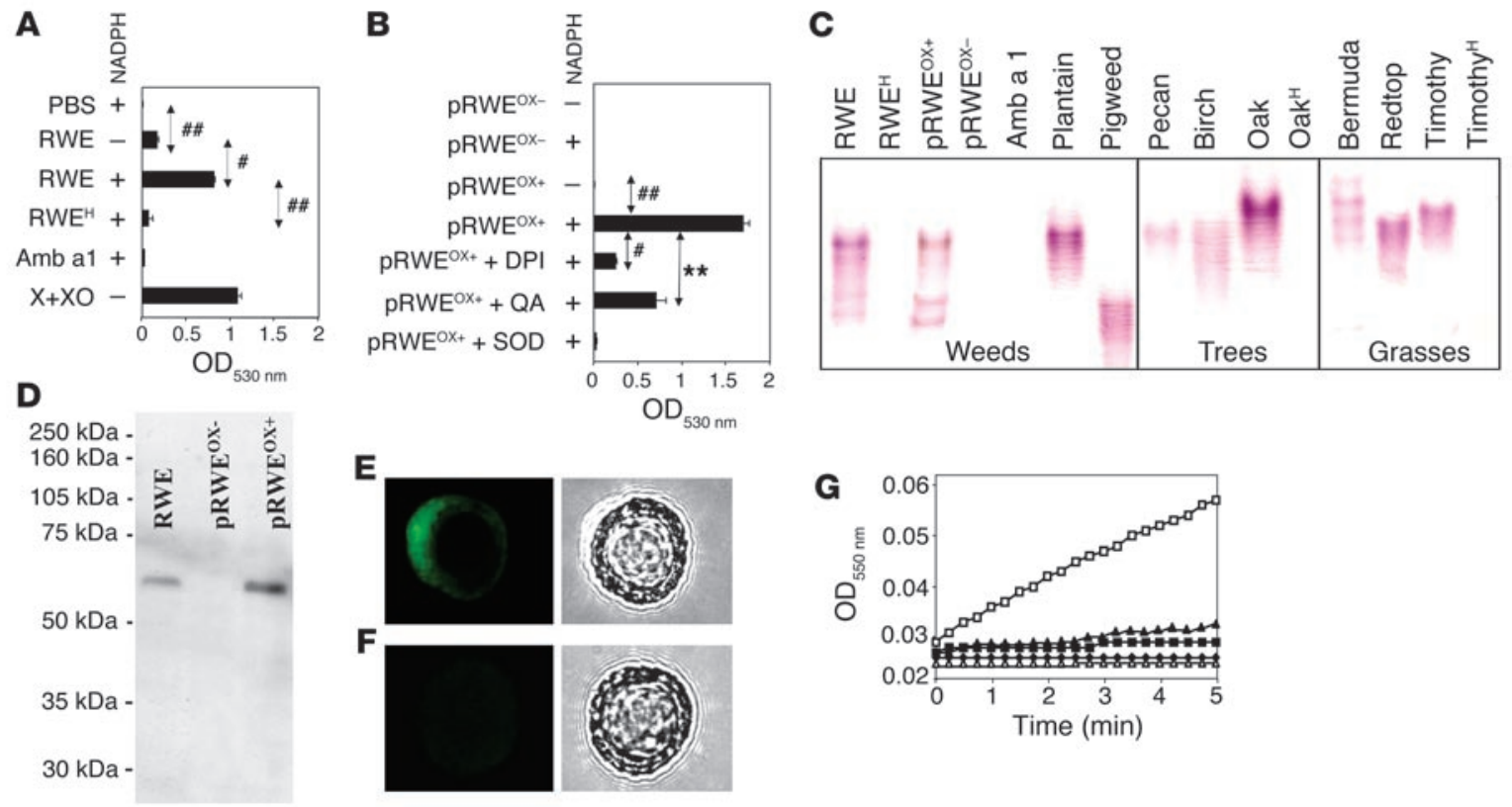

\section{Figure 1}

Pollen grain extracts show NADPH oxidase activity. (A) Reduction of NBT to formazan by allergenic extracts using NBT assay in the presence $(+)$ or absence (-) of NADPH. RWE, RWEH, and Amb a 1 were tested. $\mathrm{X}+\mathrm{XO}$ were used as a positive control. \#P<0.001; \#\# $P<0.0001$. (B)

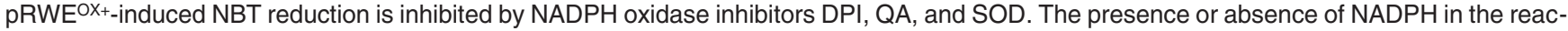
tion mixture is indicated. (C) NBT reduction by allergenic extracts in situ after nondenaturing PAGE. RWE ${ }^{H}$, heat-inactivated oak extract $\left(\mathrm{Oak}^{\mathrm{H}}\right)$, and heat-inactivated timothy grass extract $\left(\right.$ Timothy $\left.^{\mathrm{H}}\right)$ are shown. (D) Detection of p67 ${ }^{\text {phox }}$ by Western blot analysis using a rabbit anti-human p67 phox antibody. (E and F) Immunolocalization of p67phox in ragweed pollens detected by fluorescence microscopy using anti-p67phox antibody (E) or normal rabbit IgG control (F). Right panels show differential interference contrast images of the same pollens. Magnification, $\times 600$. (G) Kinetics of $\mathrm{O}_{2}{ }^{--}$generation determined by cytochrome $c$ assay. Shown are cytochrome $c$ (filled diamonds); cytochrome $c$ plus pRWEOX+ (filled squares); cytochrome $c$ plus NADPH (open triangles); cytochrome $c$ plus pRWEOX+ and NADPH (open squares); and cytochrome $c$ plus pRWE ${ }^{\mathrm{X}+}$, NADPH, and SOD (filled triangles).

to delineate their role in induction of oxidative stress and allergic inflammation in the airways. Here we describe an NADPH oxidase intrinsic to plant pollens that rapidly generates oxidative stress in the airway-lining fluid and epithelium. Our data indicate that NADPH oxidase-induced oxidative stress plays a critical role in facilitating pollen antigen-induced allergic airway inflammation.

\section{Results}

All pollens tested possessed intrinsic NADPH oxidase activity. Cells from different plant species contain oxidases that generate ROS and regulate vital physiological functions such as seed germination and root hair growth $(32,33)$. We reasoned by analogy that pollen germination is likely to require ROS generated by these oxidases during pollination processes. We used nitroblue tetrazolium (NBT) assay to determine whether extract from ragweed (Ambrosia artemisiifolia) generates ROS. RWE in solution reduced the redoxsensitive NBT to formazan (34) (Figure 1A). Adding NADPH to RWE solution boosted its ability to reduce NBT (Figure 1A). Heatinactivated RWE $\left(\mathrm{RWE}^{\mathrm{H}}\right)$ and Amb a 1, the major antigenic protein in RWE (35), failed to reduce NBT. In order to identify the NBT-reducing component, we fractionated crude RWE by Superdex 200 (Amersham Biosciences) chromatography. All 120 fractions $(1 \mathrm{ml}$ each) were tested for NBT assay and the purified RWE (pRWE) fractions with NADPH oxidase activity $\left(\mathrm{pRWE}^{\mathrm{OX}+}\right)$, as well as those without ( $\mathrm{PRWE}^{\mathrm{OX}-}$ ), were stored at $-80^{\circ} \mathrm{C}$. We also studied the ability of these fractions to oxidize redox-sensitive 2'-7'-dihydro-dichlorofluorescein diacetate $\left(\mathrm{H}_{2} \mathrm{DCF}-\mathrm{DA}\right)$ to fluorescent dichlorofluorescein (DCF). As expected, the pRWE ${ }^{+}$ fractions converted $\mathrm{H}_{2}$ DCF-DA into DCF, but pRWE ${ }^{\text {Ox- }}$ fractions failed to do so (data not shown). The ability of $\mathrm{pRWE}^{\mathrm{OX}+}$ to reduce NBT was blocked by superoxide dismutase (SOD) and by the NADPH oxidase inhibitors diphenyleneiodonium (DPI) and quinancrine (QA) (21) (Figure 1B), which suggests that NADPH oxidase is the major source of ROS. Plants have proteases and a variety of oxidases such as oxalate oxidase, amine oxidase, xanthine oxidase (XO), and glucose oxidase (31, 36-41). However, we did not find detectable activity of these enzymes in RWE fractions (data not shown). These observations suggest that NBTreducing activity in RWE fractions is due to NADPH oxidase and not to other enzymes.

To confirm these observations, we performed an in situ NBT assay on native extract proteins after nondenaturing PAGE (42). Adding NADPH to reaction buffer in the assay rapidly induced well-defined NBT-reducing protein bands in lanes with RWE and other pollen extracts (Figure 1C). Heat treatment of extracts abrogated this activity (Figure 1C). Furthermore, pollen allergen extracts from 38 other weeds, grasses, and trees induced oxidation of $\mathrm{H}_{2}$ DCF-DA to fluorescent DCF (Table 1). These findings indicate that allergenic weed, tree, and grass pollen extracts have intrinsic NADPH oxidase activity.

To validate the presence of NADPH oxidase in pollen extracts, we performed immunoblotting and immunohistochemistry 
analyses using an antibody against the p67phox component of human NADPH oxidase that cross-reacts with plant NADPH oxidase-related proteins (43). Western blot analysis identified a single band in RWE and PRWE ${ }^{\circ+}$, but not in PRWE $^{\text {OX- }}$ (Figure 1D). This antibody reacted with the periplasmic region of hydrated crosssectioned ragweed pollen grains (Figure 1, E and F). Reduction of NBT by RWE and PRWE ${ }^{\text {+ }}$ (Figure $1 \mathrm{~B}$ ) suggests that they generate superoxide radical anions $\left(\mathrm{O}_{2}{ }^{-}\right)$. We used the cytochrome $c$ assay (44) to confirm this observation. In the presence of NADPH, $\mathrm{pRWE}^{\mathrm{OX}+}$ reduced cytochrome $c$, and this reduction was abolished by SOD (Figure $1 \mathrm{G}$ ). These findings indicate that pollen NADPH oxidases generate $\mathrm{O}_{2}{ }^{--}$; this process is sensitive to NADPH oxidase inhibitors and heat treatment.

Pollen NADPH oxidases induce oxidative stress in cultured epithelial cells. Building on our initial discovery of the presence of $\mathrm{O}_{2}{ }^{-}-$-generating NADPH oxidases in pollens, we examined the effects of pollen extracts on cultured epithelial cells. RWE and pecan tree and timothy grass pollen extracts rapidly converted the intracellular redox-sensitive $\mathrm{H}_{2}$ DCF-DA in cultured A549 bronchial epithelial cells into fluorescent DCF (Figure 2A). Addition of excess NADPH to pollen extracts further increased intracellular ROS levels; this effect was attenuated by NADPH oxidase inhibitors QA and DPI. The addition of extracts and antigenic proteins that lack NADPH oxidase activity - such as RWE ${ }^{\mathrm{H}}, \mathrm{Amb}$ a 1, and PRWEOX- - failed to increase intracellular ROS levels in cultured cells (Figure 2A). In contrast, the NADPH oxidase-rich pRWE ${ }^{\mathrm{OX}+}$ increased ROS levels in A549 cells (Figure 2A). Furthermore, RWE was as effective as superoxide generator xanthine and $\mathrm{XO}(\mathrm{X}+\mathrm{XO})$ in increasing intracellular ROS levels in lung-derived National Cancer Institute (NCI) epithelial cells (NCI-H292), normal human bronchial epithelial cells (NHBE cells), and Madin-Darby canine kidney (MDCK) epithelial cells (Figure 2B). This increase in intracellular ROS was inhibited by pretreatment of cells with ROS scavenger $\mathrm{N}$-acetylcysteine (NAC) (Figure 2B). RWE was just as effective in increasing intracellular ROS levels in NHBE cells grown in air-liquid interphase (Figure 2C) (45); this effect was inhibited by NADPH oxidase inhibitors QA and DPI. pRWE ${ }^{\mathrm{XX}^{+}}$, but not pRWE ${ }^{\mathrm{OX}-}$, increased intracellular ROS levels in NHBE cells cultured in airliquid interphase (Figure 2C). These findings indicate that RWE induces oxidative stress in NHBE cells grown in physiologically relevant conditions. Prior studies have shown that extracts from pollens and house dust mites (HDMs) possess protease activity (46). Consistent with previous work, which concluded that proteases can generate ROS production in airway epithelial cells (47), adding HDM extract to cultured A549 cells induced ROS (Figure 2D); this induction was inhibited by a cocktail of protease inhibitors. In contrast, RWE-induced ROS generation was not inhibited by protease inhibitors (Figure 2D). These data indicate that the NADPH oxidase activity of pollen extracts, not their protease activity, induces intracellular ROS in cultured epithelial cells.

Intrinsic pollen NADPH oxidases induce oxidative stress in lungs. Prior studies have shown that exposure to antigens in the lungs of allergic subjects recruits inflammatory cells that produce ROS (48-50). An unresolved question is whether inhalation of pollen grains directly induces oxidative stress prior to recruitment of inflammatory cells. We hypothesized that exposure to pollen NADPH oxidases rapidly induces ROS in the lungs of mice independent of inflammation. Experiments using most models of murine allergic airway inflammation use repeated allergen challenges $(51,52)$. In such models, it is difficult to distinguish between the effects of oxidative stress generated directly by allergen exposure and ROS generated by the recruited inflammatory cells. To overcome this limitation and study events that are specifically induced by intrinsic pollen NADPH oxidases within minutes of exposure, we used a model of RWE-sensitized mice that utilizes a single intrapulmonary challenge with RWE or PBS control $(9,10,12)$. Challenge with RWE increased the levels of ROS and oxidative stress markers such as oxidized glutathione (GSSG), malondialdehyde (MDA), and 4-hydroxynonenal (4-HNE) in bronchoalveolar lavage (BAL)

\section{Table 1}

Redox activity of plant pollen extracts

\begin{tabular}{|c|c|}
\hline & DCF fluorescence ${ }^{A}$ \\
\hline \multicolumn{2}{|l|}{ Weeds } \\
\hline Ragweed & 56 \\
\hline Russian thistle & 63 \\
\hline Plantain & 158 \\
\hline Lamb's quarter & 74 \\
\hline Water hemp & 61 \\
\hline Prairie sage & 46 \\
\hline Marsh elder & 30 \\
\hline Pigweed & 91 \\
\hline Kochia & 96 \\
\hline Red sorrel & 97 \\
\hline \multicolumn{2}{|l|}{ Grasses } \\
\hline Timothy & 122 \\
\hline Orchard & 55 \\
\hline Johnson & 42 \\
\hline Salt & 359 \\
\hline Quack & 351 \\
\hline Bermuda & 47 \\
\hline Bahia & 172 \\
\hline Rye & 46 \\
\hline Redtop & 875 \\
\hline Meadow fescue & 239 \\
\hline \multicolumn{2}{|l|}{ Trees } \\
\hline Privet & 101 \\
\hline Elm & 61 \\
\hline Ash & 64 \\
\hline Oak & 258 \\
\hline Sycamore & 33 \\
\hline Hackberry & 21 \\
\hline Mt. Cedar & 102 \\
\hline Pecan & 51 \\
\hline Mesquite & 51 \\
\hline Cottonwood & 40 \\
\hline Maple & 16 \\
\hline Mulberry & 77 \\
\hline Box elder & 146 \\
\hline Bayberry & 24 \\
\hline Cypress & 269 \\
\hline Black willow & 823 \\
\hline Pine & 1 \\
\hline White poplar & 69 \\
\hline Sweetgum & 93 \\
\hline Alder & 107 \\
\hline \multicolumn{2}{|l|}{ Controls } \\
\hline Glucose oxidase & 255 \\
\hline $\mathrm{XO}$ & 320 \\
\hline
\end{tabular}

ADCF fluorescence was measured in arbitrary units generated by $500-n g$ extracts at room temperature at 30 minutes. For glucose oxidase, $1 \mu \mathrm{U} /$ well was used. For XO, $0.5 \mu \mathrm{U} /$ well was used. 


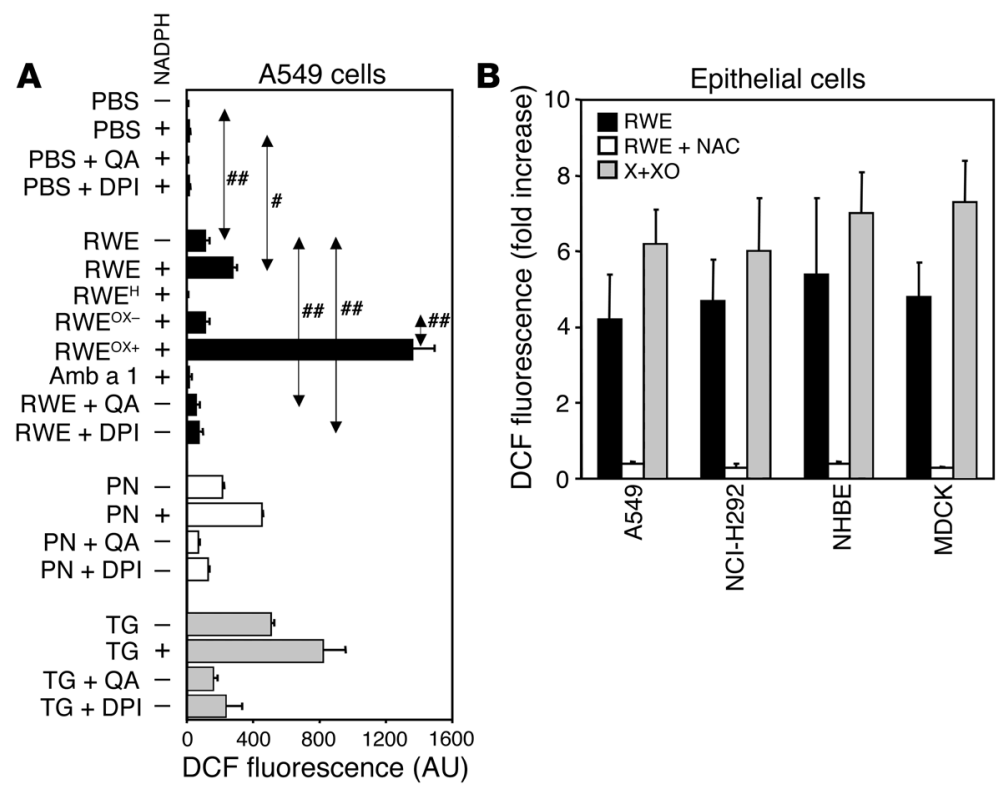

\section{Figure 2}

RWE increases ROS levels in cultured epithelial cells. (A) Effect of inhibitors of NADPH oxidase on the pollen extractinduced increase in ROS levels in A549 cells. The presence or absence of NADPH in the reaction mixture is indicated. PN, pecan tree extract; TG, timothy grass extract. ${ }^{\prime} P<0.001$; \#\# $P<0.0001$. (B) Induction of intracellular ROS by RWE in various epithelial cells and its inhibition by NAC. Shown are RWE (black bars), RWE plus NAC (white bars), and X+XO (gray bars). (C) Effect of inhibitors of NADPH oxidase on the RWE-induced increase in ROS levels in NHBE cells grown in air-liquid interphase. (D) Effect of protease inhibitors on ROS production induced by HDM extracts and RWE in A549 cells. Shown are cells with (white bars) and without (black bars) protease inhibitors.
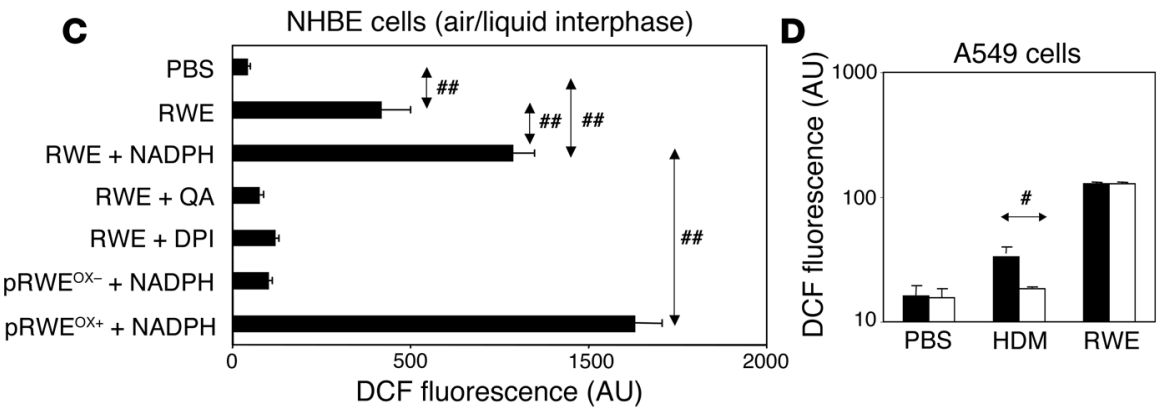

fluids (Figure 3, A and B). Challenge with pRWE ${ }^{\mathrm{OX}+}$, but not with pRWE ${ }^{\text {OX-, }}$, induced similar increases in GSSG and 4-HNE (data not shown). RWE challenge also induced intracellular ROS in the airway epithelium within 15 minutes (Figure 3, C and D). However, challenge with extracts that lack NADPH oxidase activity, such as RWE $^{\mathrm{H}}$ and $\mathrm{pRWE}^{\mathrm{OX}-}$ (Figure $3 \mathrm{C}$ ) and Amb a 1 (data not shown), failed to induce ROS in the airway epithelium. When $\mathrm{X}+\mathrm{XO}$ was coadministered with RWE $\mathrm{RW}^{\mathrm{H}}$, it reconstituted ROS levels in the epithelium. Administration of antioxidants ascorbic acid and NAC $(53,54)$ blocked elevation in lung epithelial ROS levels (Figure 3C). Sensitized mice failed to recruit inflammatory cells into the airways even at 1 hour after RWE challenge (Figure 3E), which indicates that oxidative stress in the lungs occurs prior to recruitment of inflammatory cells into the airways. These findings indicate that intrinsic pollen NADPH oxidases rapidly increase ROS levels in the lungs prior to recruitment of inflammatory cells.

Because an adaptive immune response is believed to be critical for ROS production in the airways (49), we examined the effects of RWE challenge in mice deficient in mast cells (C57BL/6J-Kit ${ }^{\mathrm{W}-\mathrm{v}}$ ) (55) and in mice deficient in B cells, T cells, and immunoglobulins (NOD SCID) (56). Challenge with RWE induced oxidative stress markers GSSG, MDA, and 4-HNE in knockout mice to levels similar to those in WT mice (Figure 3, A and B). Likewise, RWE induced levels of oxidative stress markers in naive mice that were similar to those found in RWE-sensitized mice (data not shown). These data indicate that ROS generated by intrinsic pollen NADPH oxidases induce oxidative stress in the airway epithelium and in the airwaylining fluid independent of the adaptive immune response.

ROS generated by pollen NADPH oxidases angments allergic airway inflammation. We investigated the contribution of ROS generated by pollen NADPH oxidases to the induction of allergic airway inflammation. Consistent with the results of our previous publications $(9,10,12)$, RWE challenge induced recruitment of eosinophils (Figure 4A) and total inflammatory cells (Figure 4B) in the airways. Compared with RWE challenge, intrapulmonary challenge with extracts that lack NADPH oxidase activity (RWEH and Amb a 1) recruited a significantly smaller number of eosinophils and total inflammatory cells in BAL fluids (Figure 4, A and B). The reduced ability of RWE ${ }^{\mathrm{H}}$ and $\mathrm{Amb}$ a 1 to induce inflammation could be due to their failure to stimulate Th2 cytokine production (e.g., IL-4, IL-5, IL-13). However, this possibility was ruled out as $\mathrm{RWE}^{\mathrm{H}}$ and Amb a 1 induced levels of Th2 cytokines similar to or greater than those of RWE in cultured splenocytes (Figure 4C). To quantify eosinophils and mucin-containing cells, we performed morphometric analyses of lung tissue. Similar to the findings in BAL fluid, intrapulmonary challenge with RWE ${ }^{\mathrm{H}}$ induced significantly less accumulation of eosinophils in the peribronchial area (Figure 5, A and B) and mucin-containing cells in airway epithelium (Figure 5, C and D) compared with that in RWE challenge.

Because our results (Figure $1 \mathrm{G}$ ) indicated that intrinsic pollen NADPH oxidases produce $\mathrm{O}_{2}{ }^{--}$, we predicted that administration of a surrogate $\mathrm{O}_{2}{ }^{-}$- generator should reconstitute the ability 

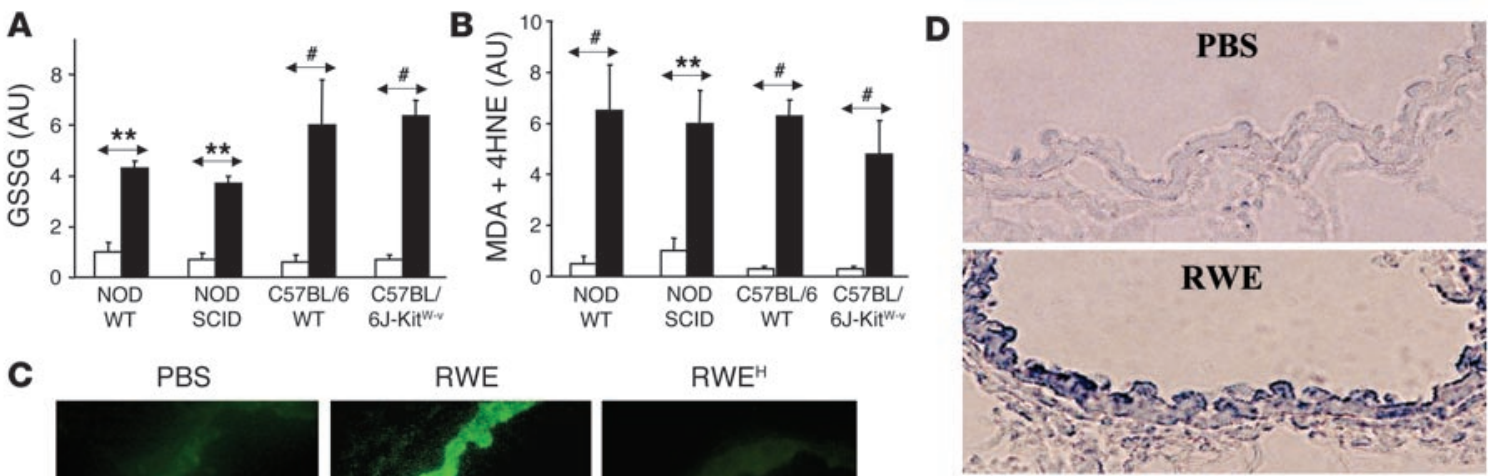

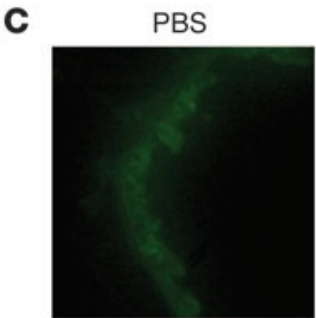

$\mathrm{RWE}^{\mathrm{H}}+\mathrm{X}+\mathrm{XO}$

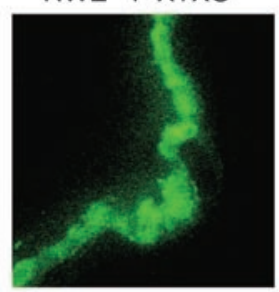

RWE

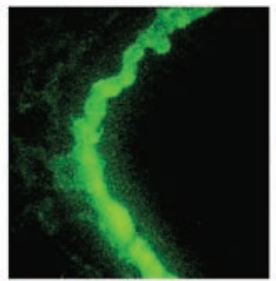

$\mathrm{RWE}+\mathrm{AA}+\mathrm{NAC}$

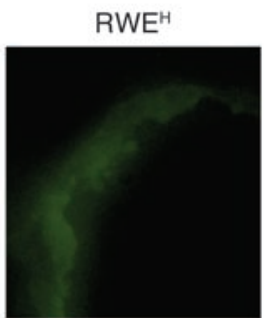

pRWE ${ }^{\circ-}$
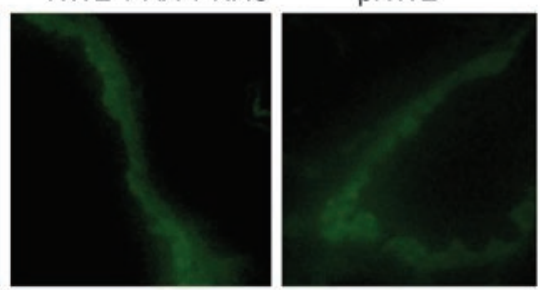

E

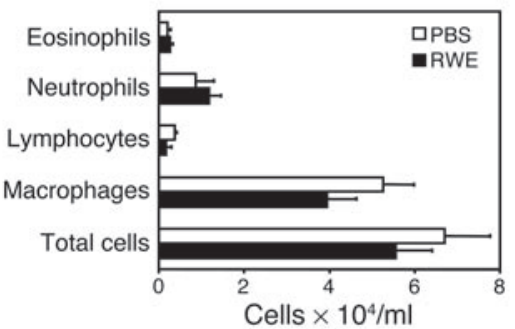

Figure 3

RWE increases oxidative stress and its markers in lungs. (A and B) Effect of RWE challenge on markers of oxidative stress GSSG (A) and MDA plus 4-HNE (B) in airway-lining fluids. Shown are PBS (white bars) and RWE (black bars; $n=4-6$ per group). Results are means \pm SEM. ${ }^{* *} P<0.01 ;{ }^{*} P<0.001$. (C and D) Change in ROS levels in lung epithelium of mice after ex vivo challenge as determined by DCF fluorescence (C) or NBT reduction (D). Magnification, $\times 100$. AA, ascorbic acid. (E) RWE challenge did not recruit inflammatory cells at 1 hour after challenge in sensitized mice. Shown are PBS (white bars) and RWE (black bars).

of $\mathrm{RWE}^{\mathrm{H}}$ and $\mathrm{Amb}$ a 1 to induce allergic inflammation. Indeed, administration of $\mathrm{X}+\mathrm{XO}$ with $\mathrm{RWE}{ }^{\mathrm{H}}$ reconstituted allergic airway inflammation (Figure 4, A and B; and Figure 5, A and B) and mucin production (Figure 5, C and D) to the levels obtained with RWE. Likewise, coadministration of $\mathrm{X}+\mathrm{XO}$ with $\mathrm{Amb}$ a 1 vigorously increased accumulation of inflammatory cells in BAL fluids (Figure 4, A and B) and the number of mucin-containing cells in the airway epithelium (Figure $5 \mathrm{E}$ ). However, administration of $\mathrm{X}+\mathrm{XO}$ by itself failed to induce inflammation (Figure 4, A and B, and Figure 5, A and B) and increase the number of mucin-containing cells (Figure 5, C and D), which indicates that ROS alone do not provide a sufficient signal to induce these effects.

To validate the importance of intrinsic pollen NADPH oxidases in the induction of allergic inflammation, we evaluated the effects of intrapulmonary challenge with PRWEOX- and coadministration of RWE with QA, a water-soluble NADPH oxidase inhibitor (21). Challenge with pRWE $^{\mathrm{OX}-}$ induced lower $\mathrm{pRWE}^{\mathrm{OX}-}$-specific IgE levels in serum than did challenge with RWE (Figure 6A). Furthermore, challenge with PRWE $^{\mathrm{OX}-}$ recruited fewer eosinophils (Figure 6B) and total inflammatory cells (Figure 6C) in BAL fluids than did challenge with RWE. Likewise, coadministration of RWE with QA inhibited recruitment of eosinophils (Figure 6B) and total inflammatory cells (Figure 6C). Together, these findings suggest that signals generated by intrinsic NADPH oxidase(s) in RWE (signal 1) boost allergic lung inflammation and the number of mucin-containing cells induced by pollen antigen (signal 2 ). To confirm this hypothesis, we challenged RWE-sensitized mice with a combination of $\mathrm{pRWE}^{\mathrm{OX}+}$ and $\mathrm{pRWE} \mathrm{OX}^{\mathrm{O}-}$ to generate signals 1 and 2. In 2 additional test groups, we removed signal 1 from challenge material either by heat inactivation of $\mathrm{PRWE}^{\mathrm{OX}+}$ or by coadministration of 4,5-dihydroxy-1,3-benzene disulfonic acid (Tiron) to scavenge superoxides (57). The combination of signals 1 and 2 induced 2.5- to 3-fold more eosinophils in the airways than did signal 1 alone (Figure 6D).

The combination of signals 1 and 2 generates robust allergic lung inflammation. Our findings suggest that 2 signals may be required for the induction of robust allergic inflammation. We hypothesized that oxidative stress generated by pollen NADPH oxidases induces an innate response, signal 1 , independent of the adaptive immune response, and that this augments allergic lung inflammation induced by pollen antigen (signal 2). Because oxidative stress is known to induce neutrophilic airway inflammation (58), we initially compared the abilities of $\mathrm{PRWE}^{\mathrm{OX}+}$ and $\mathrm{pRWE}^{\mathrm{OX}-}$ to recruit neutrophils into the airways of naive mice. Challenge of naive mice with $\mathrm{PRWE}^{\mathrm{OX}+}$ induced 7 -fold higher neutrophil recruitment at 24 hours than did challenge with PRWE $^{\text {OX- }}$ (Figure 7A). These findings indicate that oxidative stress-induced signal 1 recruits neutrophils into the lungs independent of the adaptive immune response. Because a central hallmark of signal 1 is GSSG and 4-HNE formation in the airway-lining fluid (Figure 3, A and B), we examined the contribution of these products of oxidative stress to the induction of neutrophil recruitment. Challenge of naive mice 

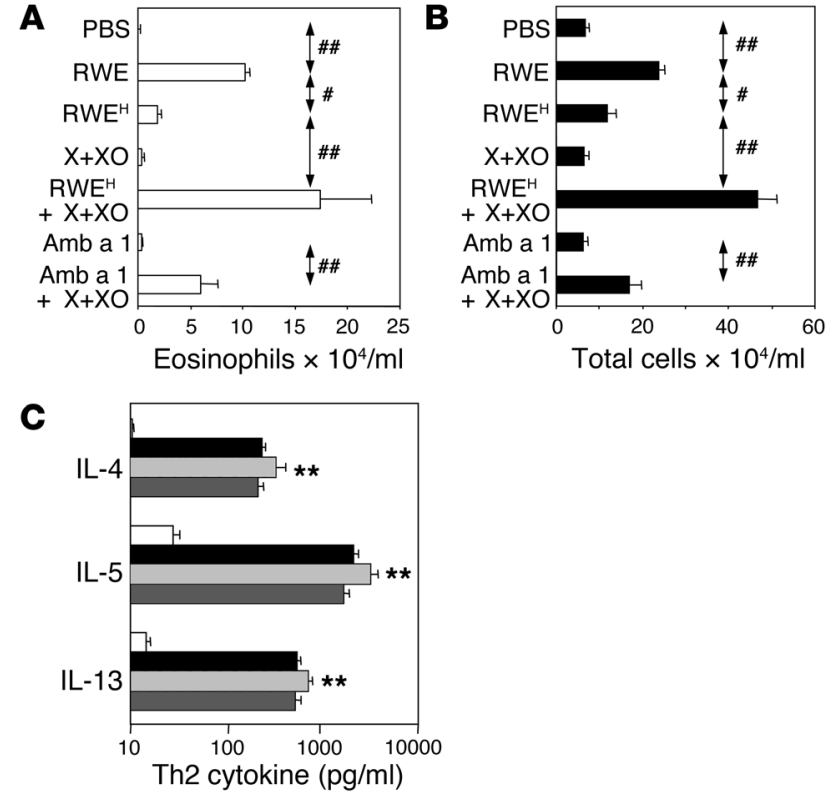

with nontoxic concentrations of GSSG and 4-HNE induced 3- to 4-fold greater neutrophil and total inflammatory cell recruitment than did challenge with PBS (Figure 7, B and C). Treatment of cultured A549 cells with GSSG and 4-HNE rapidly (within 5 minutes)

\section{Figure 4}

ROS induced by NADPH oxidase are required for allergic lung inflammation and mucin production. (A and $\mathbf{B}$ ) Removal of NADPH oxidase activity (RWEH and Amb a 1) inhibits allergic airway inflammation, and surrogate $\mathrm{O}_{2}{ }^{-}$- generator $\mathrm{X}+\mathrm{XO}$ reconstitutes $\mathrm{RWE}^{\mathrm{H}}$ - and $\mathrm{Amb}$ a $1-$ induced inflammation to the level of RWE. Results are means \pm SEM. $n=7-9$ mice per group. (C) Th2 cytokine levels in splenocyte supernatants. Splenocytes from RWE-sensitized mice were cultured with PBS (white bars), RWE (black bars), RWEH (light gray bars), or Amb a 1 (dark gray bars; $n=4-6$ per group) for 96 hours, and supernatants were analyzed by ELISA. Results are means \pm SEM. ${ }^{*} P<0.01$; $\# P<0.001 ; \# P<0.0001$.

induced tyrosine phosphorylation of p38 MAPK (Figure 7D) and subsequent production of IL-8 (Figure 7E). We also performed IL-8/luciferase reporter gene assay in order to study the effects of GSSG and 4-HNE on IL-8 promoter (59). As shown in Figure 7F, GSSG and 4-HNE induced 400- and 58-fold increases in IL-8 promoter activity, respectively. These findings suggest that activation of p38 MAPK and production of IL-8 or its murine equivalent are likely to contribute to neutrophil recruitment induced by GSSG and 4-HNE. Building on this observation, we examined the role of GSSG and 4-HNE in the modulation of antigen-induced allergic airway inflammation. Challenge of RWE-sensitized mice with Amb a 1 failed to recruit eosinophils or increase total number of inflammatory cells (Figure 7, G and H). Adding GSSG or 4-HNE to the challenge material increased eosinophil recruitment by 3 - to 4 -fold
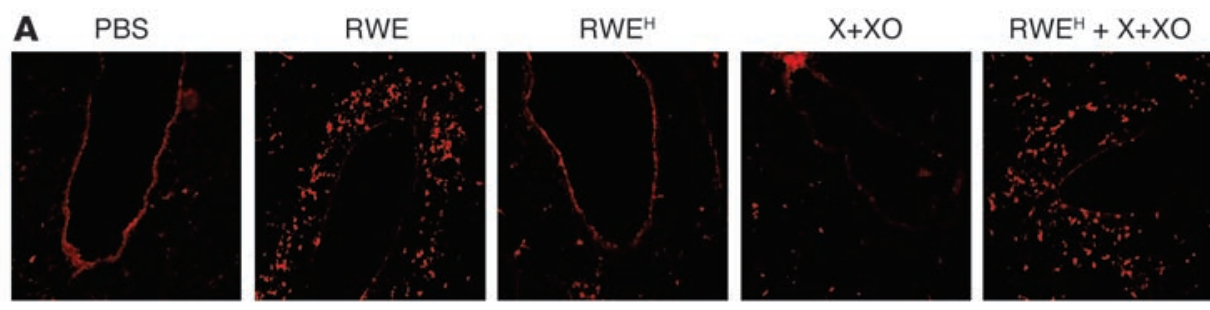

C PBS
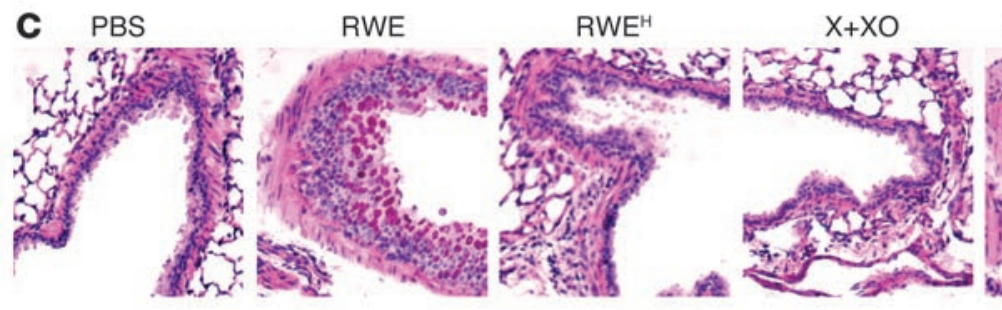

$\mathrm{RWE}+\mathrm{X}+\mathrm{XO}$

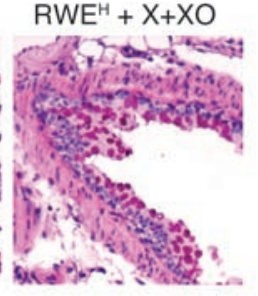

$\mathbf{E}$
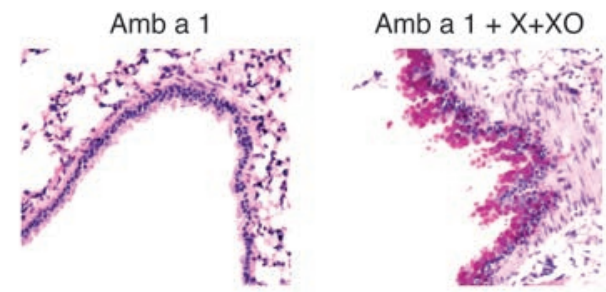

Figure 5

Removal of NADPH oxidase activity from RWE decreases accumulation of eosinophils in peribronchial location and mucin-containing cells in airway epithelium. (A) Immunohistochemical staining of lung cryosections shows accumulation of eosinophils in peribronchial regions of lungs. (B) Total eosinophil area in the peribronchial region was quantified by morphometric analysis. (C and D) Periodic acid-Schiff staining for mucin in representative lung sections. Magenta-colored epithelial cells are positive for mucin. Magnification, $\times 100$. (D) Total area of mucin-containing cells in peribronchial area was quantified by morphometric analysis. (E) Coadministration of $\mathrm{X}+\mathrm{XO}$ with Amb a 1 increases the number of mucus cells in airway epithelium. Magnification, $\times 100$. Results are means \pm SEM. $n=3-6$ mice per group. ${ }^{\#} P<0.0001$. 

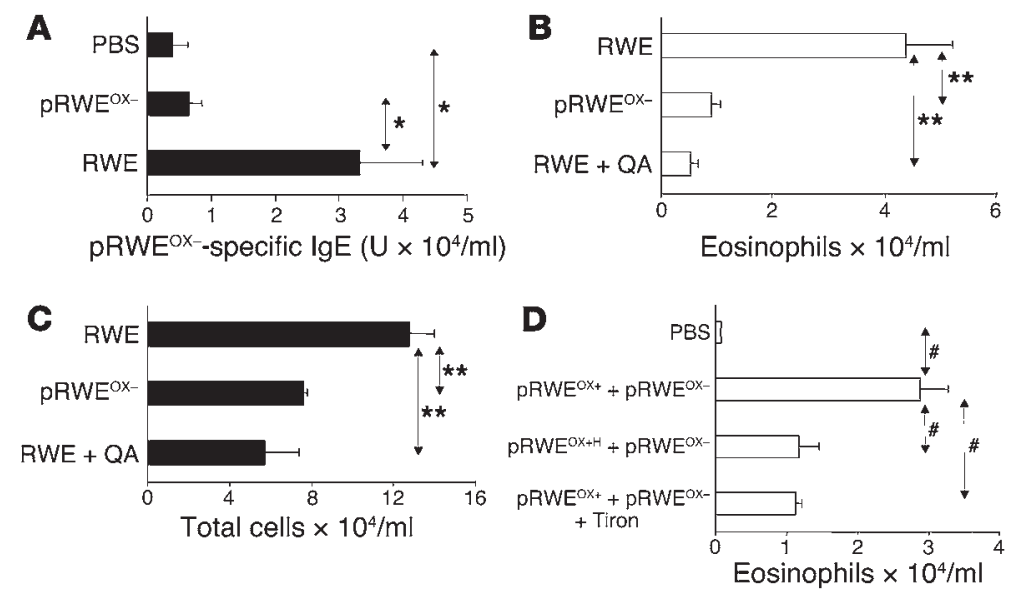

\section{Figure 6}

Removal or neutralization of intrinsic pollen NADPH oxidase of RWE reduces IgE levels and extent of allergic lung inflammation. (A) pRWEOX--specific IgE levels in serum. Mice were sensitized with RWE intraperitoneally and challenged intranasally with PBS or equal protein concentrations of either PRWEOX- or RWE. pRWEOXspecific IgE was quantified by ELISA. (B and C) RWE-sensitized mice were challenged with RWE or RWE plus QA. Adding QA inhibited RWE-induced eosinophil (B) and total inflammatory cell (C) recruitment in the airways. (D) Challenge with active NADPH fraction (pRWE ${ }^{O X}+$ plus $p R W E O x-$ ), but not inactive NADPH oxidase fractions (heat-inactivated pRWE ${ }^{\mathrm{OX}}+\left[\mathrm{pRWE}{ }^{\mathrm{O}+\mathrm{H}}\right]$ plus $\mathrm{pRWE}{ }^{\mathrm{OX}}-$ or $\mathrm{pRWE}^{\mathrm{OX}}+$ plus pRWEOX- and Tiron), induces eosinophil recruitment in the airways of RWE-sensitized animals. Results are means \pm SEM. $n=5-7$ mice per group. ${ }^{*} P<0.05$; ${ }^{* *} P<0.01 ;{ }^{\#} P<0.001$.

and total number of inflammatory cells by 2- to 3-fold (Figure 7, G and $\mathrm{H}$ ). Challenge with GSSG or 4-HNE without Amb a 1 failed to increase recruitment of eosinophils or total number of inflammatory cells (data not shown). These findings indicate that GSSG and 4-HNE produced by pollen NADPH oxidase play a significant role in augmenting antigen-induced allergic airway inflammation.

We sought to determine whether signal 1-induced events that lead to neutrophil recruitment (e.g., induction of GSSG and 4-HNE in the airway-lining fluid) can progress to allergic airway inflammation independent of the adaptive immune response. After subjecting WT and NOD SCID mice to RWE sensitization protocol, we challenged these mice with RWE to generate signals 1 and 2 in WT mice and signal 1 only in NOD SCID mice. Challenge with RWE in WT mice induced about 370- and 8-fold greater numbers of eosinophils and total inflammatory cells, respectively, than in NOD SCID mice at 72 hours (Figure 8). These data indicate that signal 1 is not sufficient to induce allergic inflammation in the absence of signal 2.

\section{Discussion}

It is currently believed that the adaptive immune response plays a crucial role in initiating Th2-mediated allergic inflammation (12). In this model, allergens are processed by dendritic cells and presented as peptides by class II MHCs to T cells (12-14). These interactions are thought to orchestrate an inflammatory cascade that leads to recruitment of eosinophils, neutrophils, lymphocytes, and macrophages about 24-72 hours after allergen challenge (12-14). In the present study we demonstrate for the first time to our knowledge that pollen extracts from weeds, trees, and grasses have intrinsic NADPH oxidase activity that induces ROS in airway epithelium within minutes, independent of the adap- tive immune response. Our data add a new dimension to the existing paradigm of initiation of allergic inflammation because we show that this NADPH oxidase-induced ROS vigorously augments specific IgE production and allergic airway inflammation induced by the major pollen antigens.

We propose a 2-signal ROS-antigen model for the initiation of allergic inflammation. In this model, ROS generated by pollen NADPH oxidases induce oxidative stress (signal 1) independent of the adaptive immune response. Products generated by oxidative stress such as GSSG and 4-HNE facilitate allergic airway inflammation induced by pollen antigen (signal 2 ). The impact of signal 1 is observed at 24 hours after challenge as neutrophil recruitment independent of adaptive immunity, but its effect fades by 72 hours after challenge unless the adaptive immune response facilitates the process. This model explains why pollen proteins that lack NADPH oxidases and consequently cannot deliver signal 1 (Amb a $1, \mathrm{RWE}^{\mathrm{H}}$, and pRWE ${ }^{\mathrm{OX}-}$ ) are unable to induce robust allergic lung inflammation. Our data demonstrate that signal 1 does not have to be specifically induced by NADPH oxidases because it can be replaced by a surrogate system of ROS generation (i.e., $\mathrm{X}+\mathrm{XO}$ ). The immunological specificity of the system comes from signal 2.

In previous studies, we (58) and others (60) have shown that oxidative stress in the lungs can increase expression of inflammatory chemokines and induce recruitment of neutrophils. Our present data indicate that pollen NADPH oxidases induce 4-HNE and GSSG in airwaylining fluid and that these contribute to IL- 8 production, p38 MAPK activation, and neutrophil recruitment. It is conceivable that upon exposure, pollen NADPH oxidases contribute to significant oxidative stress and induce severe neutrophil-dominant asthma and sudden-onset fatal asthma as previously reported by us (2) and others (61).

Prior reports show that exposure of patients to a combination of antigen and ozone augments allergic inflammation $(60,62,63)$. In these studies, oxidative stress in the lungs is delivered by ozone present in the environment. Our present data, which indicate that pollen NADPH oxidases (signal 1) boost allergic lung inflammation induced by a pollen antigen (signal 2), extend these observations, because oxidative stress is delivered as a package with antigen. In our model, the addition of an electron to $\mathrm{O}_{2}$ by the pollen NADPH oxidase results in the formation of $\mathrm{O}_{2}{ }^{\circ}$. One important function of $\mathrm{O}_{2}{ }^{-}$is to reduce $\mathrm{Fe}^{3+}$ to $\mathrm{Fe}^{2+}$, which is required for the generation of the hydroxyl radical $\left({ }^{\circ} \mathrm{OH}\right)$. Another characteristic of $\mathrm{O}_{2}{ }^{-}{ }^{-}$is to react with ${ }^{\circ} \mathrm{NO}$, which is present in the airway-lining fluid (50) and combines with $\mathrm{O}_{2}{ }^{-}-$to form highly reactive peroxynitrite anion ('ONOO). ${ }^{\circ} \mathrm{ONOO}$ is then protonated to form an unstable species, $\mathrm{HONOO}$, which leads to the production of ${ }^{\circ} \mathrm{OH}, \mathrm{NO}_{2}^{-}$, and $\mathrm{NO}_{3}{ }^{-}$by homolytic cleavage (64). Airway-lining fluid contains extracellular SOD (65), which can reduce $\mathrm{O}_{2}{ }^{-}$to $\mathrm{H}_{2} \mathrm{O}_{2} \cdot \mathrm{H}_{2} \mathrm{O}_{2}$ can be further reduced to the hydroxyl radical in the presence of $\mathrm{Fe}^{2+}$ (known as the Fenton reaction). $\mathrm{H}_{2} \mathrm{O}_{2}$ can also be metabolized to hypochlorous acid $(\mathrm{HOCl})$ by myloperoxidase in the presence of chloride. $\mathrm{H}_{2} \mathrm{O}_{2}$ and $\cdot \mathrm{OH}$ can react with lipids to form lipid hydroperoxides (and consequently MDA and/or 4-HNE), which may explain their presence in BAL fluid minutes after RWE challenge as found in the 

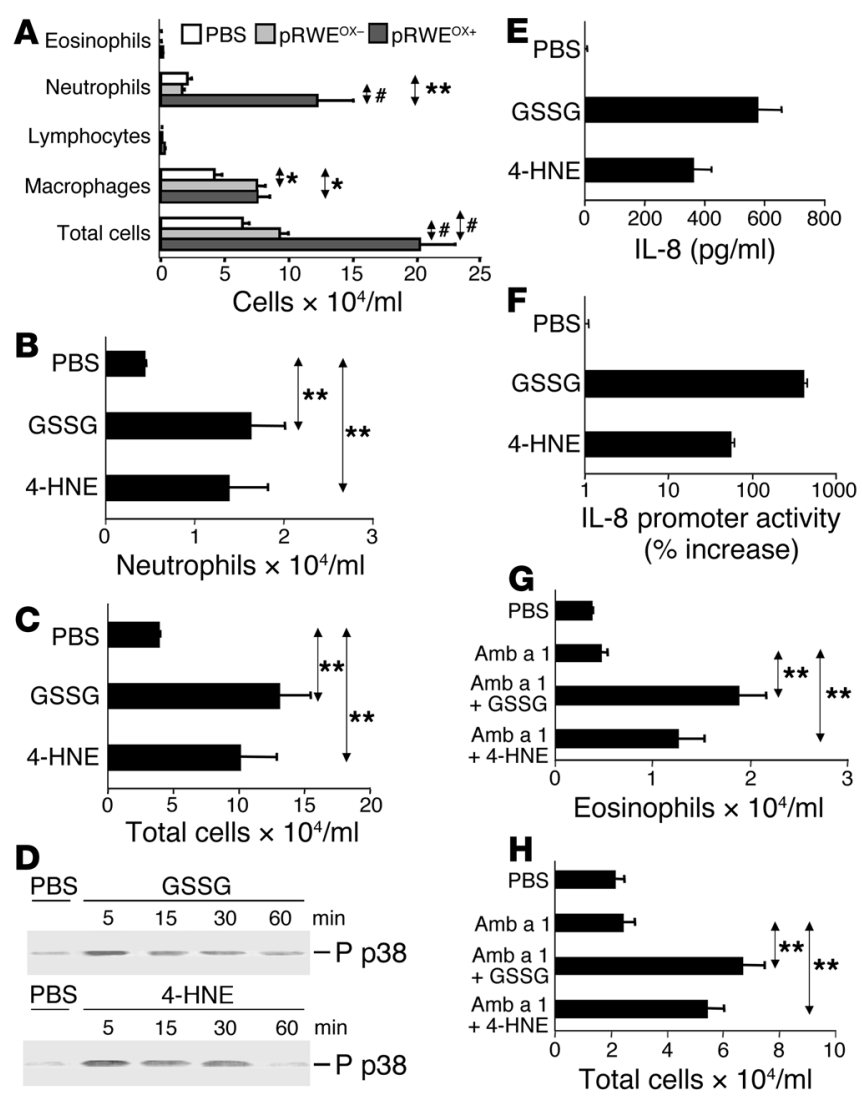

present study. Levels of 4-HNE are elevated in the lungs of patients with chronic obstructive pulmonary disease (66). This highly reactive diffusible product of lipid peroxidation is a key mediator of oxidant-induced cell signaling and apoptosis (67).

In the present study, we show that pollen NADPH oxidases induce ROS independent of the adaptive immune response. In a previous study, partial amino acid sequence identity was reported among Pyr c 5, Bet v 6 , and a plant protein related to a defense mechanism. This was termed phenylcoumaran benzylic ether reductase (PCBER) based on its ability to catalyze the NADPH-dependent reduction of $8^{\prime}-5^{\prime}$ linked lignans such as dehydrodiconiferyl alcohol to produce isodihydro-dehydrodiconiferyl alcohol (68). The authors showed that Pyr c 5 triggered a strong, dose-dependent mediator release from basophils of a pear-allergic subject, which suggests that Pyr $\mathrm{c} 5$ has the potential to elicit type I allergic reactions. However, PCBER differs from the pollen NADPH oxidases used in our study because PCBER generates alcohol in the presence of NADPH, whereas pollen NADPH oxidases generate ROS. Furthermore, PCBER elicits IgE-mediated basophil degranulation, whereas pollen NADPH oxidases generate oxidative stress in the lungs independent of IgE, mast cells, and adaptive immunity. In another report, NADP-thioredoxin reductase was reported to reduce disulfide bonds in allergens in the presence of NADPH, thereby decreasing IgE-mediated allergenicity of wheat proteins (69). Thus, its actions are distinct from pollen NADPH oxidases that generate ROS and augment pollen antigenmediated allergic inflammation.

Conventional models of the immune response are based on distinguishing self from non-self. An intriguing "danger model" has recently been proposed for the activation of immune responses (70). In this model, damaged or stressed tissues generate factors

\section{Figure 7}

Impact of signal 1 on airway inflammation. (A) Recruitment of inflammatory cells induced by challenge with pRWEOX+ and pRWEOX- in naive mice at 24 hours. (B and C) Effect of GSSG and 4-HNE challenge on recruitment of neutrophils $(B)$ and total inflammatory cells (C) in naive mice at 24 hours. (D) GSSG and 4-HNE induce tyrosine phosphorylation (P) of p38 MAPK in cultured A549 cells in a timedependent manner. (E and F) GSSG and 4-HNE induce IL-8 production (E) and IL-8 promoter activity (F) in A549 cells. (G and H) GSSG and 4-HNE augment Amb a 1-induced recruitment of eosinophils (G) and total number of inflammatory cells $(\mathbf{H})$ in RWE-sensitized mice.

that activate antigen-presenting cells. It has recently been proposed that intrinsic proteases in HDMs induce a "danger signal" that facilitates allergic sensitization to mite antigens (71). Investigation of whether ROS induction by pollen NADPH oxidases constitutes a danger signal is needed.

In the current study we showed that pollen NADPH oxidase can induce specific IgE production. We further showed that 39 out of 40 tested pollen extracts had detectable redox activity. The only pollen extract that failed to demonstrate redox activity was from pine. This finding is consistent with previous reports that even though pine pollens are present in large quantities in the environment, they fail to induce allergic sensitization in humans (72, 73). Our results suggest that specific inhibitors of pollen NADPH oxidases may prevent allergic airway inflammation. However, the relevance of our study to human asthma remains circumstantial, and the observed mechanism needs to be established in patients with atopic disease.

\section{Methods}

RWE. Endotoxin-free RWE (lot XP56-D18-1320) was purchased from Greer Laboratories. All experiments were performed with ragweed because it is an allergen relevant to human allergic asthma. We previously showed that patients with allergic asthma challenged subsegmentally with RWE and other allergens mount late-phase airway inflammation that is predominantly either neutrophilic or eosinophilic, depending on the quantity of endotoxin in the allergenic extract (74). Because asthma is an eosinophilic disease of the airways, we used endotoxin-free RWE in the current study.

Cell cultures and treatments. Cells were obtained from ATCC (A549, NCI$\mathrm{H} 292$, and MDCK) and maintained according to the supplier's instructions. NHBE cells were obtained from Cambrex Bioproducts (catalog no.

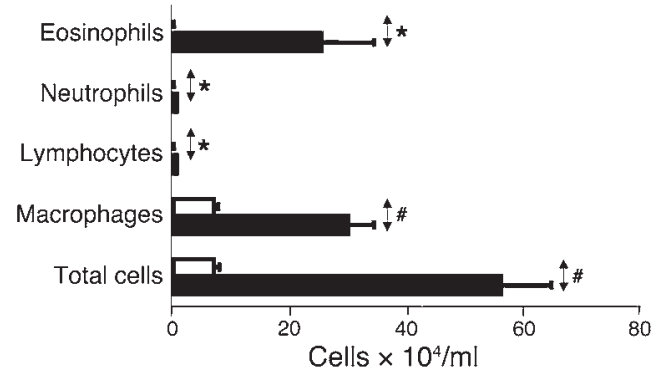

Figure 8

Presence of signal 2 (antigen) is required to induce allergic airway inflammation. RWE induces significantly higher inflammation in the airways in WT mice (capable of processing antigen [signal 2] and redox activity [signal 1]; black bars) at 72 hours compared to that in SCID mice (capable of processing redox activity [signal 1] only; white bars). ${ }^{*} P<0.05 ;{ }^{\#} P<0.001$. 
CC-2641, lot no. 3F0404) and were cultured on 12-well transwell membranes coated with collagen $(0.4 \mu \mathrm{m}$ pore size; Corning Costar). The air-liquid interface was established when the cells reached confluence in culture as previously described $(45,75)$. Cells were maintained in a humidified $\mathrm{CO}_{2}$ $(5 \%)$ incubator and medium as recommended by the suppliers. To detect p38 MAPK phosphorylation, $2 \times 10^{5}$ A549 cells were cultured per well for 12 hours and washed with PBS. Cells were starved in serum-free media for 4 hours and then treated with either PBS, 5 mM GSSG, or $250 \mathrm{nM}$ 4-HNE for 5-60 minutes. Immediately after incubation the cells were lysed and used for Western blot analysis.

Splenocytes were incubated at $5 \times 10^{6}$ cells $/ \mathrm{ml}$ with either diluent or allergenic extracts $(100 \mu \mathrm{g} / \mathrm{ml})$ for 4 days. The cells were incubated in complete medium as mentioned above.

Animals, sensitization, and challenge. Animal experiments were performed according to the NIH Guide for Care and Use of Experimental Animals and were approved by the UTMB Animal Care and Use Committee (approval no. 97-08-038). Six- to 8-week-old female BALB/c, C57BL/6 WT, C57BL/6J-

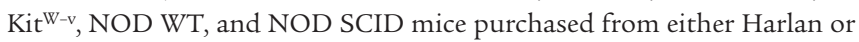
The Jackson Laboratory were used for these studies. Airway inflammation was induced with RWE (Greer Laboratories) sensitization and challenges $(5,6,10)$. Briefly, mice were sensitized once with $150 \mu \mathrm{g} / \mathrm{mouse}$ RWE mixed with alum (day 0 ) and again 4 days later (day 4), as previously described (6, 9). On day 11, parallel groups of mice were challenged intranasally with RWE $(100 \mu \mathrm{g}), \mathrm{RWE}^{\mathrm{H}}(100 \mu \mathrm{g})$, or Amb a $1(10 \mu \mathrm{g})$. In selected experiments, xanthine $(0.32 \mathrm{mM})$ and $\mathrm{XO}\left(50 \mathrm{mU}\right.$; Sigma-Aldrich) were mixed with $\mathrm{RWE}^{\mathrm{H}}$ or Amb a 1. In some experiments, mice were challenged with either $12 \mu \mathrm{M}$ GSSG or $75 \mu \mathrm{M} 4$-HNE per mouse or in combination with Amb a 1.

Evaluation of allergic inflammation. Cellular infiltration into the airway lumen was assessed by an analysis of BAL fluid at 72 hours after challenge, as we have described previously $(5,6,10,58)$.

NBT assay. Pollen grain extract proteins $(50 \mu \mathrm{g} /$ assay) were mixed with NBT $(2 \mathrm{mM})$ with or without NADPH $(100 \mu \mathrm{M})$. Mixtures were then incubated for 15 minutes at $37^{\circ} \mathrm{C}$, and the sediment formazan was dissolved in methanol. OD was determined at $530 \mathrm{~nm}$ in a spectrophotometer (DU 530; Beckman Coulter).

In situ gel NBT assay. Allergen extracts (50 $\mu \mathrm{g}$ per lane) were electrophoresed on a $6 \%$ nondenaturing polyacrylamide gel at $4^{\circ} \mathrm{C}$. The gel was immersed in NBT solution ( $2 \mathrm{mM})$, and NADPH $(1 \mathrm{mM})$ was added. The gel was photographed when color developed.

Western blot analysis. Proteins were separated on a 10\% SDS-polyacrylamide gel and blotted onto Hybond membranes (Amersham Biosciences). Blots were incubated in a blocking buffer containing 5\% BSA in TBST buffer (20 mM Tris-base; $137 \mathrm{mM} \mathrm{NaCl}, \mathrm{pH} 7.6$; and 0.05\% Tween 20) for 1 hour, followed by incubation in the primary $\mathrm{Ab}$ (rabbit polyclonal anti-human p67phox, catalog no. SC-15342; Santa Cruz Biotechnology Inc.) for 1 hour. Alternatively, for $\mathrm{p} 38 \mathrm{MAPK}$ analysis, affinity-purified rabbit polyclonal $\mathrm{Ab}$ against phosphorylated p38 MAPK (New England Biolabs) was used. After washing 5 times in TBST buffer, blots were incubated for 30 minutes with an HRP-conjugated secondary $\mathrm{Ab}$ (donkey anti-rabbit antibody conjugated to HRP, catalog no. NA 934; Amersham Biosciences). The blots were developed with the enhanced chemiluminescence (ECL; Amersham Biosciences) substrate according to the manufacturer's protocol.

Immunofluorescence studies. For immunolocalization of NADPH oxidase, cryosections of pollen grains were fixed with acetone/methanol (1:1) and incubated with anti-human p67phox for 30 minutes at $37^{\circ} \mathrm{C}$. After 3 washes with PBS-Tween 20, anti-rabbit FITC-conjugated IgG antibody (catalog no. SC-2359; Santa Cruz Biotechnology Inc.) was added and incubated as described above. The sections mounted in antifade solution (Fluorescent Mounting Medium, catalog no. S3023; DAKO Inc.) were examined using an inverted Nikon Eclipse TE 200 fluorescent microscope attached to a
Photometrix CoolSNAP Fx CCD digital camera and MetaMorph software (version 5; Universal Imaging Corp.).

Cytochrome $c$ assay. To detect $\mathrm{O}_{2}{ }^{--}$, the cytochrome $c$ assay was used as described by Messner and Imaly (44). The assay was carried out in PBS with $10 \mu \mathrm{g}$ PRWE and $10 \mu \mathrm{M}$ oxidized cytochrome $c$ in the reaction mixture. The reaction was started by adding $100 \mu \mathrm{M} \mathrm{NADPH}$, and the increase in $\mathrm{A}_{550 \mathrm{~nm}}$ was recorded for 5 minutes. Saturating amounts of SOD $(50 \mathrm{U} / \mathrm{ml})$ were used in a reference reaction to determine any $\mathrm{O}_{2}{ }^{-}$-independent direct reduction of cytochrome $c$ by the sample.

Measurement of oxalate, amine, glucose, and XO activity. We used Amplex Red (10-acetyl-3,7-dihydroxyphenoxazine; Invitrogen Corp.) assay to determine oxidase activity per the manufacturer's protocol. Amplex Red reacts with $\mathrm{H}_{2} \mathrm{O}_{2}$ in the presence of HRP to generate a stable product, resorufin (76). Briefly, RWE fractions $(100 \mu \mathrm{g} / \mathrm{ml})$ were suspended in $100 \mu \mathrm{l}$ reaction buffer, then incubated at room temperature $\left(25^{\circ} \mathrm{C}\right)$ for 30 minutes with 0.25 $\mathrm{U} / \mathrm{ml}$ Amplex Red (determined in preliminary studies) and $1 \mathrm{U} / \mathrm{ml} \mathrm{HRP}$. The change in fluorescence was measured using a microplate reader (SpectraMass M2; Molecular Devices). Reactions were carried out with or without exogenously added SOD. The addition of catalase (400 U/ml; SigmaAldrich) decreased $\mathrm{H}_{2} \mathrm{O}_{2}$ levels by approximately $90 \%$.

Measurement of ROS in cultured epithelial cells. Cells (A549, NCI-H292, NHBE, and MDCK) grown to $70 \%$ confluence were loaded with $50 \mu \mathrm{M}$ $\mathrm{H}_{2}$ DCF-DA at $37^{\circ} \mathrm{C}$ for 15 minutes. Alternatively, NHBE cells grown in air-liquid interphase were loaded with $50 \mu \mathrm{M} \mathrm{H}_{2}$ DCF-DA at $37^{\circ} \mathrm{C}$ for 15 minutes from the basolateral surface. After we removed excess probes, cells were treated with RWE with or without NADPH $(100 \mu \mathrm{M})$ and with or without the NADPH oxidase inhibitors QA $(500 \mu \mathrm{M})$ and DPI $(100 \mu \mathrm{M})$. In selected experiments, plant protease inhibitor cocktail in 1:100 dilution (no. P2714; Sigma-Aldrich) was added. This protease inhibitor cocktail contained the following components: $2 \mathrm{mM}$ 4-(2-aminoethyl) benzenesulfonylfluoride. $\mathrm{HCl}$ (serine protease inhibitor), $1 \mathrm{mM}$ EDTA (metalloprotease inhibitor), $130 \mu \mathrm{M}$ bestatin (aminopeptidase inhibitor), $14 \mu \mathrm{M}$ E-64 (cysteine protease inhibitor), $1 \mu \mathrm{M}$ leupeptin (serine and cysteine protease inhibitor), and $0.3 \mu \mathrm{M}$ aprotinin (serine protease inhibitor). The change in fluorescence intensity was assessed in a FLx800 microplate reader (BioTek) or in selected experiments by flow cytometry (FACScan; BD Biosciences) (77) at 488-nm excitation and 530-nm emission. Each data point of FACS analysis represents the mean fluorescence for 12,000 cells from 3 or more independent experiments and is expressed as \pm SEM.

Measurement of ROS in airway epithelium ex vivo. Mice were sensitized to RWE, and on day 11 the airway epithelium was loaded by intrapulmonary administration of chloromethyl- $\mathrm{H}_{2}$ DCF-DA (Invitrogen Corp.) or NBT (Invitrogen Corp.). After removing excess probe, the lungs were challenged with RWE $(100 \mu \mathrm{g})$ ex vivo. Intraluminal RWE was removed 15 minutes after challenge. The lungs were then inflated and embedded in Optical Cutting Temperature (O.C.T.; Sakura Finetek), frozen, and sectioned. Oxidized products of redox-sensitive probes were analyzed using a Photometrix CoolSNAP Fx CCD digital camera mounted on a Nikon Eclipse TE 200 fluorescent microscope.

Measurement of GSSG, MDA, and 4-HNE. Naive and RWE-sensitized (BALB/c, NOD SCID or C57BL/6) mice were challenged with RWE (100 $\mu \mathrm{g})$, and BAL fluids were collected after 30 minutes. BAL fluids were clarified by centrifugation $\left(956 \mathrm{~g}\right.$ for 10 minutes at $4^{\circ} \mathrm{C}$ ), and aliquots were stored at $-80^{\circ} \mathrm{C}$. Butylated hydroxytoluene $(0.5 \mathrm{mM}$; Sigma-Aldrich) was added to prevent further lipid oxidation in some aliquots. GSSG levels were measured spectrophotometrically at $412 \mathrm{~nm}$ using a glutathione/GSSG-412 kit (Bioxytech; OXIS). MDA and 4-HNE were quantified using an LPO-586 assay kit (OXIS) and absorbance was measured at $580 \mathrm{~nm}$.

Quantitation of cytokines. The splenocyte cell supernatants were examined by a 2 -site immunoenzymetric assay for IL-4 (clones 1D11 and 24G2; 
Pierce Biotechnology Inc.), IL-5 (clones TRFK5 and TRFK4, BD Biosciences - Pharmingen), and IL-13 (clone 38213 and catalog no. BAF413; R\&D Systems). IL-8 in A549 culture supernatant was measured by 2-site immunoenzymetric assay for IL-8 using an ELISA kit (catalog no. KHC0081; Biosource International).

Morphometric quantitation of peribronchial eosinophils. Cryosections of O.C.T.-fixed lungs were incubated with rabbit anti-mouse eosinophil major basic protein (anti-MBP, a generous gift from G.J. Gleich, Mayo Clinic, Rochester, Minnesota, USA) or normal rabbit serum, then with goat anti-rabbit Alexa Fluor 488-conjugated antibody (Invitrogen Corp.). The stained sections were photographed with a Photometrix CoolSNAP Fx CCD digital camera mounted on a Nikon Eclipse TE 200 fluorescent microscope. Morphometric analyses were performed to quantify number and area of eosinophils using MetaMorph software (version 5; Universal Imaging Corp.). Five to 6 images from 5 different levels per lung $(n=3$ animals per group) were obtained and reassembled using the MetaMorph software montage stage stitching algorithm (78). The integrated morphometric analysis function was used to transform total pixel area of the fluorescent signal from the eosinophils into $\mu \mathrm{m}^{2}$ units after calibration (79). The data were represented as area of eosinophils (fluorescent signal) in $\mu \mathrm{m}^{2}$ per millimeter of total peribronchial area. Mucin production in the epithelial cells was assessed by periodic acid-Schiff staining of formalinfixed, paraffin-embedded lung sections and quantified by MetaMorph software as described above.

Dual luciferase assay. A549 cells were grown in 24-well plates to 70\% confluence and transiently cotransfected with IL-8 luciferase reporter plasmid (a generous gift from A.R. Brasier, UTMB, Galveston, Texas, USA) and phRLTK Renilla Luciferase plasmid (Promega) vectors at a 10:1 ratio. Twelve hours after transfection, cells were treated with either PBS, $250 \mathrm{nM}$ 4-HNE, or $5 \mathrm{mM}$ GSSG dissolved in PBS. The luciferase activities were measured with the Dual Luciferase Reporter Assay System (Promega) as directed by the manufacturer. Briefly, triplicate samples containing $1.5 \times 10^{5}$ cells each were lysed with $100 \mu \mathrm{L}$ lysing buffer (Dual Luciferase Kit; Promega) 12 hours after the treatment. The cellular debris were removed from the supernatants by centrifugation. Aliquots of $20 \mu \mathrm{L}$ of the supernatants were added to the Renilla and Firefly luciferase substrate solution, and the amount of light emitted by the sample was measured by Lucy2 Luminometer (Anthos Labtec Instruments $\mathrm{GmbH}$ ). Results are means \pm SEM of normalized percentage increase $(n=3)$.

Quantitation of pRWE-specific IgE. pRWE-specific IgE was measured in serum samples by 1-site immunoenzymetric assay. Briefly, microtiter wells were coated with pRWE and probed with biotin anti-mouse IgE (R35-72; BD Biosciences - Pharmingen). Plates were developed with avidin-alkaline phosphatase enzyme (Sigma-Aldrich) and pNPP substrate (Sigma-Aldrich).

Statistics. Data from different treatment groups were analyzed by ANOVA, followed by Bonferroni post-hoc analyses for least significant difference. Differences were considered significant at $P<0.05$.

\section{Acknowledgments}

We acknowledge B.K. Sur for his expertise in antioxidants, A. Estrada for contributing to quantitation of mucin by morphometric analyses, and D. Konkel for critically reading the manuscript. Research was supported by a National Institute of Environmental Health and Sciences Center grant (ES06676, to I. Boldogh), NIH grants 1R01HL071163-01A2 and P01 AI46004 (to S. Sur) and CA84461 (to I. Boldogh), a National Heart, Lung, and Blood Institute Proteomics initiative (N01-HV28184; to A. Kurosky and S. Sur), and a UTMB pilot project grant (to S. Sur).

Received for publication January 7, 2005, and accepted in revised form May 10, 2005.

Address correspondence to: Sanjiv Sur, NIH Asthma and Allergic Diseases Research Center and the Department of Internal Medicine, University of Texas Medical Branch, 8.104 Medical Research Building, 301 University Boulevard, Galveston, Texas 77555, USA. Phone: (409) 772-3411; Fax: (409) 772-5841; E-mail: sasur@utmb.edu.

Istvan Boldogh, Attila Bacsi, Barun K. Choudhury, and Nilesh Dharajiya contributed equally to this work.
1. Bousquet, J., et al. 1990. Eosinophilic inflammation in asthma. N. Engl. J. Med. 323:1033-1039.

2. Sur, S., et al. 1993. Sudden-onset fatal asthma. A distinct entity with few eosinophils and relatively more neutrophils in the airway submucosa? Am Rev. Respir. Dis. 148:713-719.

3. Gleich, G.J., et al. 1987. The eosinophilic leukocyte and the pathology of fatal bronchial asthma: evidence for pathologic heterogeneity. J. Allergy Clin. Immunol. 80:412-415

4. Lee, J.J., et al. 2004. Defining a link with asthma in mice congenitally deficient in eosinophils. Science. 305:1773-1776.

5. Sur, S., Kita, H., Gleich, G.J., Chenier, T.C., and Hunt, L.W. 1996. Eosinophil recruitment is associated with IL-5, but not with RANTES, twenty-four hours after allergen challenge. J. Allergy Clin. Immunol. 97:1272-1278.

6. Sur, S., et al. 1995. Allergen challenge in asthma: association of eosinophils and lymphocytes with interleukin-5. Allergy. 50:891-898.

7. Jarjour, N.N., et al. 1997. The immediate and late allergic response to segmental bronchopulmonary provocation in asthma. Am. J. Respir. Crit. Care Med. 155:1515-1521.

8. Sedgwick, J.B., et al. 1992. Comparison of airway and blood eosinophil function after in vivo antigen challenge. J. Immunol. 149:3710-3718.

9. Sur, S., et al. 1996. Immunomodulatory effects of IL-12 on allergic lung inflammation depend on timing of doses. J. Immunol. 157:4173-4180.
10. Sur, S., et al. 1999. Long term prevention of allergic lung inflammation in a mouse model of asthma by CPG oligodeoxynucleotides. J. Immunol. 162:6284-6293.

11. Sur, S., Bouchard, P., Holbert, D., and Van Scott, M.R. 2000. Mucosal IL-12 inhibits airway reactivity to methacholine and respiratory failure in murine asthma. Exp. Lung Res. 26:477-489.

12. Wild, J.S., et al. 2000. IFN-gamma-inducing factor (IL-18) increases allergic sensitization, serum IgE, Th2 cytokines, and airway eosinophilia in a mouse model of allergic asthma. J. Immunol. 164:2701-2710.

13. Choudhury, B.K., et al. 2002. In vivo role of p38 mitogen-activated protein kinase in mediating the anti-inflammatory effects of CPG oligodeoxynucleotide in murine asthma. J. Immunol. 169:5955-5961.

14. Sedgwick, J.B., et al. 1992. Comparison of airway and blood eosinophil function after in vivo antigen challenge. J. Immunol. 149:3710-3718.

15. Creticos, P.S., et al. 1996. Ragweed immunotherapy in adult asthma. N. Engl. J. Med. 334:501-506.

16. Walker, S.M., Pajno, G.B., Lima, M.T., Wilson, D.R., and Durham, S.R. 2001. Grass pollen immunotherapy for seasonal rhinitis and asthma: a randomized, controlled trial. J. Allergy Clin. Immunol. 107:87-93.

17. Taylor, P.E., Flagan, R.C., Valenta, R., and Glovsky, M.M. 2002. Release of allergens as respirable aerosols: a link between grass pollen and asthma. J. Allergy Clin. Immunol. 109:51-56.
18. Michel, F.B., Marty, J.P., Quet, L., and Cour, P. 1977. Penetration of inhaled pollen into the respiratory tract. Am. Rev. Respir. Dis. 115:609-616.

19. Wanner, A., Russi, E., Brodnan, J.M., Danta, I., and Gazeroglu, H. 1985. Prolonged bronchial obstruction after a single antigen challenge in ragweed asthma. J. Allergy Clin. Immunol. 76:177-181.

20. Gadermaier, G., et al. 2004. Biology of weed pollen allergens. Curr. Allergy Asthma Rep. 4:391-400.

21. Van Gestelen, P., Asard, H., and Caubergs, R.J. 1997. Solubilization and separation of a plant plasma membrane NADPH-O2- synthase from other NAD(P)H oxidoreductases. Plant Physiol. 115:543-550.

22. Doke, N., et al. 1996. The oxidative burst protects plants against pathogen attack: mechanism and role as an emergency signal for plant bio-defence-a review. Gene. 179:45-51.

23. Murphy, T.M., Vu, H., and Nguyen, T. 1998. The superoxide synthases of rose cells. Comparison of assays. Plant Physiol. 117:1301-1315.

24. Frahry, G., and Schopfer, P. 2001. NADH-stimulated, cyanide-resistant superoxide production in maize coleoptiles analyzed with a tetrazoliumbased assay. Planta. 212:175-183.

25. Wojtaszek, P. 1997. Oxidative burst: an early plant response to pathogen infection [review]. Biochem.J. 322:681-692.

26. Yoshioka, H., et al. 2001. Induction of plant gp91 phox homolog by fungal cell wall, arachidonic acid, and salicylic acid in potato. Mol. Plant Microbe 
Interact. 14:725-736.

27. Sagi, M., and Fluhr, R. 2001. Superoxide production by plant homologues of the gp91(phox) NADPH oxidase. Modulation of activity by calcium and by tobacco mosaic virus infection. Plant Physiol. 126:1281-1290.

28. Schopfer, P., Plachy, C., and Frahry, G. 2001. Release of reactive oxygen intermediates (superoxide radicals, hydrogen peroxide, and hydroxyl radicals) and peroxidase in germinating radish seeds controlled by light, gibberellin, and abscisic acid. Plant Physiol. 125:1591-602.

29. Papadakis, A.K., and Roubelakis-Angelakis, K.A. 1999. The generation of active oxygen species differs in tobacco and grapevine mesophyll protoplasts. Plant Physiol. 121:197-206.

30. Foreman, J., et al. 2003. Reactive oxygen species produced by NADPH oxidase regulate plant cell growth. Nature. 422:442-446.

31. Bagarozzi, D.A., and Travis, J. 1998. Ragweed pollen proteolytic enzymes: possible roles in allergies and asthma. Phytochemistry. 47:593-598.

32. Barr, R. 1991. The possible role of redox-associated protons in growth of plant cells. J. Bioenerg. Biomembr. 23:443-467.

33. Foreman, J., et al. 2003. Reactive oxygen species produced by NADPH oxidase regulate plant cell growth. Nature. 422:442-446.

34. Liochev, S.I., and Fridovich, I. 1995. Superoxide from glucose oxidase or from nitroblue tetrazolium? Arch. Biochem. Biophys. 318:408-410.

35. Rafnar, T., et al. 1991. Cloning of Amb a I (antigen E), the major allergen family of short ragweed pollen. J. Biol. Chem. 266:1229-1236.

36. Bagarozzi, D.A., Potempa, J., and Travis, J. 1998. Purification and characterization of an arginine-specific peptidase from ragweed (Ambrosia artemisiifolia) pollen. Am. J. Respir. Cell Mol. Biol. 18:363-369.

37. Bagarozzi, D.A., Jr., Pike, R., Potempa, J., and Travis, J. 1996. Purification and characterization of a novel endopeptidase in ragweed (Ambrosia artemisiifolia) pollen. J. Biol. Chem. 271:26227-26232.

38. Vianello, A., and Macri, F. 1991. Generation of superoxide anion and hydrogen peroxide at the surface of plant cells. J. Bioenerg. Biomembr. 23:409-423.

39. Caliskan, M., Turet, M., and Cuming, A.C. 2004. Formation of wheat (Triticum aestivum L.) embryogenic callus involves peroxide-generating germin-like oxalate oxidase. Planta. 219:132-140.

40. Lane, B.G. 2000. Oxalate oxidases and differentiating surface structure in wheat: germins. Biochem. J. 349:309-321.

41. Carter, C.J., and Thornburg, R.W. 2004. Tobacco nectarin $\mathrm{V}$ is a flavin-containing berberine bridge enzyme-like protein with glucose oxidase activity. Plant Physiol. 134:460-469.

42. Lopez-Huertas, E., Corpas, F.J., Sandalio, L.M., and Del Rio, L.A. 1999. Characterization of membrane polypeptides from pea leaf peroxisomes involved in superoxide radical generation. Biochem. $J$. 337:531-536.

43. Dwyer, S.C., Legendre, L., Low, P.S., and Leto, T.L. 1996. Plant and human neutrophil oxidative burst complexes contain immunologically related proteins. Biochim. Biophys. Acta. 1289:231-237.

44. Messner, K.R., and Imlay, J.A. 2002. In vitro quantitation of biological superoxide and hydrogen per- oxide generation. Methods Enzymol. 349:354-361.

45. Booth, B.W., Adler, K.B., Bonner, J.C., Tournier, F., and Martin, L.D. 2001. Interleukin-13 induces proliferation of human airway epithelial cells in vitro via a mechanism mediated by transforming growth factor-alpha. Am. J. Respir. Cell Mol. Biol. 25:739-743.

46. Bagarozzi, D.A., Potempa, J., and Travis, J. 1998. Purification and characterization of an arginine-specific peptidase from ragweed (Ambrosia artemisiifolia) pollen. Am. J. Respir. Cell Mol. Biol. 18:363-369.

47. Wan, H., et al. 1999. Der p 1 facilitates transepithelial allergen delivery by disruption of tight junctions. J. Clin. Invest. 104:123-133.

48. Calhoun, W.J., Reed, H.E., Moest, D.R., and Stevens, C.A. 1992. Enhanced superoxide production by alveolar macrophages and air-space cells, airway inflammation, and alveolar macrophage density changes after segmental antigen bronchoprovocation in allergic subjects. Am. Rev. Respir. Dis. 145:317-325.

49. Sanders, S.P., et al. 1995. Spontaneous oxygen radical production at sites of antigen challenge in allergic subjects. Am. J. Respir. Crit. Care Med. 151:1725-1733.

50. Crapo, J.D., and Day, B.J. 1999. Modulation of nitric oxide responses in asthma by extracellular antioxidants. J. Allergy Clin. Immunol. 104:743-746.

51. Grunig, G., et al. 1998. Requirement for IL-13 independently of IL-4 in experimental asthma. Science. 282:2261-2263.

52. Akbari, O., et al. 2003. Essential role of NKT cells producing IL-4 and IL-13 in the development of allergen-induced airway hyperreactivity. Nat. Med. 9:582-588.

53. Som, S., Raha, C., and Chatterjee, I.B. 1983. Ascorbic acid: a scavenger of superoxide radical. Acta Vitaminol. Enzymol. 5:243-250.

54. Urban, T., Akerlund, B., Jarstrand, C., and Lindeke, B. 1997. Neutrophil function and glutathione-peroxidase (GSH-px) activity in healthy individuals after treatment with N-acetyl-L-cysteine. Biomed. Pharmacother. 51:388-390.

55. Kawakami, T. and Galli, S.J. 2002. Regulation of mast-cell and basophil function and survival by IgE. Nat. Rev. Immunol. 2:773-786.

56. Lapidot, T., Fajerman, Y., and Kollet, O. 1997. Immune-deficient SCID and NOD/SCID mice models as functional assays for studying normal and malignant human hematopoiesis. J. Mol. Med. 75:664-673.

57. Jung, O., et al. 2004. gp91phox-containing NADPH oxidase mediates endothelial dysfunction in renovascular hypertension. Circulation. 109:1795-1801.

58. Michalec, L., et al. 2002. CCL7 and CXCL10 orchestrate oxidative stress-induced neutrophilic lung inflammation. J. Immunol. 168:846-852.

59. Garofalo, R., et al. 1996. Transcriptional activation of the interleukin-8 gene by respiratory syncytial virus infection in alveolar epithelial cells: nuclear translocation of the RelA transcription factor as a mechanism producing airway mucosal inflammation. J. Virol. 70:8773-8781.

60. Depuydt, P.O., Lambrecht, B.N., Joos, G.F., and Pauwels, R.A. 2002. Effect of ozone exposure on allergic sensitization and airway inflammation induced by dendritic cells. Clin. Exp. Allergy. 32:391-396.

61. Jatakanon, A., et al. 1999. Neutrophilic inflamma- tion in severe persistent asthma. Am. J. Respir. Crit. Care Med. 160:1532-1539.

62. Neuhaus-Steinmetz, U., Uffhausen, F., Herz, U., and Renz, H. 2000. Priming of allergic immune responses by repeated ozone exposure in mice. Am. J. Respir. Cell Mol. Biol. 23:228-233.

63. Peden, D.B., Boehlecke, B., Horstman, D., and Devlin, R. 1997. Prolonged acute exposure to $0.16 \mathrm{ppm}$ ozone induces eosinophilic airway inflammation in asthmatic subjects with allergies. J. Allergy Clin. Immunol. 100:802-808.

64. Mulligan, M.S., Hevel, J.M., Marletta, M.A., and Ward, P.A. 1991. Tissue injury caused by deposition of immune complexes is L-arginine dependent. Proc. Natl. Acad. Sci. U. S. A. 88:6338-6342.

65. Oury, T.D., Day, B.J., and Crapo, J.D. 1996. Extracellular superoxide dismutase in vessels and airways of humans and baboons. Free Radic. Biol. Med. 20:957-965.

66. Rahman, I., et al. 2002. 4-Hydroxy-2-nonenal, a specific lipid peroxidation product, is elevated in lungs of patients with chronic obstructive pulmonary disease. Am. J. Respir. Crit. Care Med. 166:490-495.

67. Karamloo, F., et al. 2001. Phenylcoumaran benzylic ether and isoflavonoid reductases are a new class of cross-reactive allergens in birch pollen, fruits and vegetables. Eur. J. Biochem. 268:5310-5320.

68. Buchanan, B.B., et al. 1997. Thioredoxin-linked mitigation of allergic responses to wheat. Proc. Natl. Acad. Sci. U. S. A. 94:5372-5377.

69. Matzinger, P. 2002. The danger model: a renewed sense of self. Science. 296:301-305.

70. Gallucci, S., and Matzinger, P. 2001. Danger signals: SOS to the immune system [review]. Curr. Opin. Immunol. 13:114-119.

71. Bousquet, J., Cour, P., Guerin, B., and Michel, F.B. 1984. Allergy in the Mediterranean area. I. Pollen counts and pollinosis of Montpellier. Clin. Allergy. 14:249-258.

72. Harris, R.M., and German, D.F. 1985. The incidence of pine pollen reactivity in an allergic atopic population. Ann. Allergy. 55:678-679.

73. Hunt, L.W., et al. 1994. Endotoxin contamination causes neutrophilia following pulmonary allergen challenge. Am. J. Respir. Crit. Care Med. 149:1471-1475.

74. Krunkosky, T.M., et al. 2000. Effects of TNF-alpha on expression of ICAM-1 in human airway epithelial cells in vitro. Signaling pathways controlling surface and gene expression. Am. J. Respir. Cell Mol. Biol. 22:685-692.

75. Zhou, M., Diwu, Z., Panchuk-Voloshina, N., and Haugland, R.P. 1997. A stable nonfluorescent derivative of resorufin for the fluorometric determination of trace hydrogen peroxide: applications in detecting the activity of phagocyte NADPH oxidase and other oxidases. Anal. Biochem. 253:162-168.

76. Ribardo, D.A., et al. 2002. Early cell signaling by the cytotoxic enterotoxin of Aeromonas hydrophila in macrophages. Microb. Pathog. 32:149-163.

77. Loo, B.W., Jr., Meyer-Ilse, W., and Rothman, S.S. 2000. Automatic image acquisition, calibration and montage assembly for biological X-ray microscopy. J. Microsc. 197:185-201.

78. Klimaschewski, L., Nindl, W., Pimpl, M., Waltinger, P., and Pfaller, K. 2002. Biolistic transfection and morphological analysis of cultured sympathetic neurons. J. Neurosi. Methods. 113:63-71. 